DOI: https://doi.org/10.35699/2237-5864.2018.2337

\title{
CONCEPÇÕES DE MANEJO DE RESÍDUOS QUIIMICOS POR PARTE DE UM GRUPO DE LICENCIANDOS EM QUÍMICA DO CAA/UFPE'
}

\author{
Yrailma Katharine de Sousa² \\ Regina Célia Barbosa de Oliveira² \\ Agilson Nascimento de Souza²
}

\section{RESUMO}

Esta pesquisa, de natureza qualitativa, do tipo descritivo, teve como objetivo analisar a influência da formação docente em Química do Centro Acadêmico do Agreste, da Universidade Federal de Pernambuco, nas concepções dos licenciandos quanto ao manejo de resíduos químicos. Para isso, tomamos como base a Lei $n^{\circ} 12.305$, que institui a Política Nacional dos Resíduos Sólidos, e a Lei n 9.795, que trata da inclusão da Educação Ambiental em todos os estágios de ensino. A metodologia empregada constituiu-se da realização de entrevistas semiestruturadas, com alguns discentes do curso. O conteúdo dos extratos das entrevistas foi analisado dentro da proposta de análise de conteúdo de Bardin. A análise dos dados mostrou que os licenciandos apresentaram limitações quanto à compreensão sobre o manejo adequado de resíduos químicos, embora tenham sido evidenciadas, nas falas de alguns discentes, características que remetem às relações entre as aulas experimentais do curso e o manejo de resíduos, bem como à reflexão quanto às práticas socioambientais deles na condição de futuros docentes.

Palavras-chave: Manejo de resíduos. Educação Ambiental. Formação docente em Química.

\footnotetext{
${ }^{1}$ Centro Acadêmico do Agreste, Universidade Federal de Pernambuco.

${ }^{2}$ Centro Acadêmico do Agreste, Universidade Federal de Pernambuco, Caruaru, PE, Brasil.
} 


\section{CONCEPTIONS OF CHEMICAL WASTE}

MANAGEMENT BY A GROUP OF CHEMISTRY GRADUATES IN CAA/UFPE

Yrailma Katharine de Sousa

Regina Célia Barbosa de Oliveira

Agilson Nascimento de Souza

\section{ABSTRACT}

This qualitative/descriptive search aimed to analyze the influence of teacher education in Chemistry of the Agreste Academic Center of the Federal University of Pernambuco, in the conceptions of the graduating students about chemical residues management. For this, we took as basis the Law No. 12,305, which institues the National Policy on Solid Waste, and Law No. 9,795, that provides the inclusion of environmental education in all educational institutions. The methodology used consisted of semi-structured interviews with some graduating students. The content of the interviews extracts was analyzed according to the proposal of Bardin content analysis. The examination of the data showed that the graduating students presented limitations on understanding the adequate chemical residues management, although some characteristics have been evidenced by students, which refer to the relations between experimental classes of the course and residues management, as well as their reflection on socio environmental practices as future teachers.

Keywords: Waste management. Environmental education. Chemistry teacher education. 


\section{INTRODUÇÃO}

Segundo Martins et al. (2014), no Brasil, o aumento dos resíduos gerados sem cuidados adequados vem ocasionando diversos problemas para a saúde pública e ambiental. Não só no Brasil, mas nas sociedades como um todo, questões ambientais têm sido tema de discussões em diversos eventos e conferências, como a Conferência de Estocolmo e conferências realizadas em 1992, 2002 e 2012, no Rio de Janeiro (ABREU; CAMPOS; AGUILAR, 2008; PORTO, 1998; TRISTÃO, 2008).

As discussões levantadas nessas conferências contribuíram, em certa medida, para as políticas ambientais e, por conseguinte, para a elaboração de leis que exigem a abordagem de questões ambientais nas disciplinas das universidades e demais instituições de ensino, por exemplo, a Lei $n^{\circ} 9.795$, regulamentada pelo Decreto $n^{\circ} 4.281$, no ano de 2002, que determina a inserção obrigatória da Educação Ambiental em todos os estágios de ensino brasileiro (ABREU; CAMPOS; AGUILAR, 2008).

Em consonância com a legislação, pensamos que os cursos de formação docente possuem grande responsabilidade em proporcionar aos licenciandos uma formação inicial pautada em discussões pertinentes sobre a temática "sustentabilidade" e que propicie o pensamento reflexivo e crítico dos profissionais, cuja prática deve ser permeada por ações socioeducativas. Conforme Zeichner (1993), a reflexão crítica das ações dos profissionais da educação possibilita a habilidade de se trabalharem conscientemente temas fundamentais para o ensino.

Entretanto, a inserção das discussões sobre questões ambientais nos cursos de licenciatura em Química nas universidades é atual. Conforme Abreu, Campos e Aguilar (2008), a maioria das universidades apresenta a temática em disciplinas optativas ou em eletivas e, de certa forma, limitada à abordagem de temas como preservação ambiental, escassez de água e poluição. Em face dessa limitação, acreditamos que haja precarização de articulação política e pedagógica, no sentido de superar a visão despolitizada, acrítica e naturalista na prática da Educação Ambiental, conforme sugerem as Diretrizes Curriculares para Educação Ambiental (BRASIL, 2012).

Nesse contexto, concordamos com as diretrizes, pois pensamos que discussões simplistas podem propiciar uma visão reducionista sobre o conteúdo, que está inteiramente voltado ao cotidiano. 
Acerca dessa discussão, Jardim (1998) destaca que as universidades devem trabalhar com mais ênfase as questões de manejo adequado dos resíduos químicos, principalmente nos departamentos de Química, onde há licenciandos envolvidos em atividades geradoras de resíduos químicos e, por conseguinte, a necessidade da realização do manejo adequado. Em consonância com Jardim, pensamos que os espaços de formação de professores de Química deveriam ser permeados de discussões e conteúdos procedimentais relativos ao manejo de resíduos, na perspectiva de sensibilizar os licenciandos quanto à preservação do meio ambiente e ao uso sustentável dos recursos do laboratório, e que esses licenciandos possam reproduzir esse modelo reflexivo nas práticas socioeducativas que exercerem.

Assim, motivados por questionamentos relativos aos desdobramentos da formação de professores de Química voltada para questões socioambientais, nos propomos a analisar a influência da formação de licenciandos em Química nas concepções deles acerca do manejo de resíduos químicos, para responder às seguintes questões: estaria o curso de QuímicaLicenciatura favorecendo a compreensão de seus licenciandos quanto à necessidade de manejo adequado de resíduos químicos? Os licenciandos de Química conseguem estabelecer relações entre as aulas experimentais do curso e o manejo de resíduos?

\section{ENSINO DE QUÍMICA NO BRASIL: INFLUÊNCIAS HISTÓRICAS E IMPLICAÇÕES}

O ensino de Química no Brasil sofreu forte influência de alguns acontecimentos históricos desencadeados ainda no período que compreendeu o Brasil colônia. Nesse período, o Brasil apresentava-se como sociedade apêndice de Portugal, e, como consequência desse modelo, as práticas relacionadas ao ato de ensinar, no Brasil, estavam subordinadas às orientações da Universidade de Lisboa e de outros centros de ensino europeu, com repercussão no redirecionamento de concepções das ciências. Um dos desdobramentos da influência portuguesa diz respeito à definição dos currículos de Química, permeados pela dicotomia entre teoria e prática, que derivam a separação entre ensino e pesquisa, a discriminação quanto a estudantes de licenciaturas, a desvinculação das disciplinas de conteúdo pedagógico e o distanciamento entre formação acadêmica e questões da prática docente na escola (SOUZA, 2009).

Acerca dessas discussões, Maldaner (2000, p. 51) comenta que "os currículos de formação profissional, com base na racionalidade técnica derivada do positivismo, ainda presente em algumas instituições de ensino superior, tendem a separar o mundo acadêmico da prática 
e, assim, manter o monopólio da pesquisa". Fato que remete ao artifício histórico de fortalecimento da dependência da grande massa populacional.

Nesse sentido, Souza (2009) argumenta que o ensino de Química, desde o início da República, trilhou caminhos desvirtuados de questões mais concretas da sociedade, o que, em certa medida, inviabilizou a construção dessa ciência com viés perspectivamente crítico. Conforme o mesmo autor, ainda nos dias de hoje, é possível identificar cursos de formação de professor tradicionalmente conteudistas que estão aquém das necessidades de uma sociedade globalizada, cujos anseios demandam modelos de formação potencialmente emancipacionistas.

O referido autor alerta ainda para a verticalização do conhecimento, o que potencializa a marginalização dos saberes populares construídos histórica e coletivamente pelos grupos sociais. Adotou-se e, de certa maneira, adota-se a prática de copiar/importar saberes universitários e, portanto, considerados superiores. Essa prática, segundo Chassot (1995), foi muito mais fortalecida pela crença de países emergentes de conquistar a emancipação pelo conhecimento da ciência em relação aos países dominadores do que pela imposição dos colonizadores.

Segundo Tardif (2014), os saberes docentes não devem se reduzir apenas aos saberes do conteúdo disciplinar e de transmissão. Os saberes supracitados são importantes, mas há diversos saberes intrínsecos à formação docente que propiciam melhor processo de ensinoaprendizagem, principalmente no ensino de Química. A relação entre esses saberes poderá permitir maior reflexão dos professores na prática de ensino que realizam e distanciamento do modelo técnico (TARDIF, 2014).

Nesse sentido, John Dewey é o primeiro pesquisador que insere nas discussões que apresenta a necessidade da reflexão do professor. Dewey (1959, apud SOUZA; MARTINELI, 2009) considera que o processo de ensino-aprendizagem é alcançado com mais significância quando o professor para e analisa criticamente a própria postura e as atividades que ministra em sala de aula. Após Dewey, Donald Schön, grande pesquisador, propõe um modelo para a formação de profissionais reflexivos (SOUZA, 2009). Schön (2007, apud SOUZA, 2009, p. 39) "pôs-se defensor do 'ensino prático reflexivo' - a reflexão-na-ação- como modo de atingir um ensino de competências profissionais que podem ajudar a resolver problemas reais, do cotidiano". A proposta contida no modelo dele influencia o ensino, permitindo uma amplitude do docente 
perante as análises críticas de suas atividades. Na perspectiva de Schön, a ação reflexiva está permeada de três aspectos: a reflexão na prática, a reflexão da prática e a reflexão sobre e na prática, e, a partir delas, procura-se rever as ações de modo a torná-las mais proveitosas (DARSIE; CARVALHO, 1996; SOUZA, 2009).

Sobretudo Souza (2009) ressalta que a teoria do professor reflexivo, na perspectiva de Schön, apresentaria ainda algumas limitações, na medida em que não considera, por exemplo, repercussões político-sociais.

Souza, Silva e Silva (2013) entendem a docência como ação que deve ser consciente, politizada e voltada para questões sociais mais amplas, e, por assim, pensarem, os autores estão mais alinhados com a perspectiva de Zeichner (1993). Este autor discorre que a prática docente deve estar atrelada ao contexto estrutural político e sugere que, para isso, o processo de reflexão deve voltar-se não apenas para a própria prática, mas também para como a prática exercida atende ou interfere no contexto social, além de considerar a riqueza das experiências vivenciadas em sala de aula pelos professores.

Contudo, reconhecemos que os cursos de formação inicial de professores, tradicionalmente, têm apresentado perfil bacharelista, pela ausência de reflexões sobre o conhecimento científico produzido na sala de aula, a qual, para Schön (1992) e Maldaner (2000), está alicerçada na racionalidade técnica, com acúmulo de conhecimentos específicos e pedagógicos desvinculados entre si e das necessidades adequadas à atuação em sala. Resgatamos, nesse sentido, o pensamento de Pereira (2000), que alerta para a necessidade de romper com a visão simplista de formação de professor, de negar a ideia de transmissor de conhecimentos e superar modelos de licenciatura baseados na sobreposição do processo de ensino pelos conteúdos.

Sensibilizados pela necessidade de mudanças no processo de formação docente, bem como no ensino de Química, acreditamos que a predominância de modelos de formação permeados por influências acadêmicas recebidas acriticamente abre precedentes para novas discussões acerca dos desafios da formação docente em Química no século XXI, e, dentro desse escopo, insere-se a Educação Ambiental, principalmente nos cursos que desenvolvem atividades experimentais sem a preocupação com o destino dado aos resíduos gerados nessas atividades. Em face dessa situação, consideramos relevante analisar as contribuições do curso Química- 
Licenciatura do CAA-UFPE para a formação de profissionais mais críticos, que, no mínimo, possam atuar em articulação com contextos socioambientais.

A seguir, apresentamos alguns aspectos relativos à inserção da Educação Ambiental no contexto da formação de professores de Química, esses aspectos deram suporte à nossa pesquisa.

\section{ASPECTOS RELACIONADOS À INSERÇÃO DA EDUCAÇÃO AMBIENTAL EM CURSOS DE LICENCIATURA EM QUÍMICA}

Conforme Tristão (2008), as repercussões de um mundo globalizado perpassaram a necessidade de ampliação das discussões acerca da educação ambiental para o desenvolvimento de uma sociedade sustentável, em eventos mundiais e locais. A Conferência de Estocolmo, nos anos 1970, por exemplo, foi o ponto crucial para a identificação de problemas ambientais. Por meio das discussões levantadas na ocasião, foram criadas iniciativas que repercutiram nos espaços de formação acadêmica, como a inserção da Educação Ambiental na educação formal e não formal (MEDINA, 2008), muito embora a Educação Ambiental tenha se tornado componente obrigatório no currículo dos cursos de ensino superior apenas em 2002, com a Lei $n^{\circ}$ 9.795, regulamentada pelo Decreto $n^{\circ} 4.281$, que institui a Política Nacional da Educação Ambiental.

Outro marco importante para a Educação Ambiental foi a elaboração da Carta de Bogotá, em 1985, no Caribe, cujos desdobramentos contemplaram tentativas de integrar comunidades acadêmicas em ações estratégicas em torno da temática (TRISTÃO, 2008). Ainda assim, o autor enfatiza que, para além dos muros das instituições, a Educação Ambiental deve repercutir na sociedade como um todo, a partir da formação de sujeitos críticos-reflexivos, distanciandose da formação ambiental livresca. Resgatamos essa preocupação na definição de Educação Ambiental do Ministério do Meio Ambiente (MMA) como

processos por meio dos quais o indivíduo e a coletividade constroem valores sociais, conhecimentos, habilidades, atitudes e competências voltadas para a conservação do meio ambiente, bem de uso comum do povo, essencial à sadia qualidade de vida e sua sustentabilidade (MMA, 2017, p. 1).

À luz dessas interpretações, vai se delineando que a Educação Ambiental constitui um dos desafios da formação docente em Química no século XXI, sobre o paradigma de formar 
profissionais mais críticos, que, no mínimo, possam atuar em articulação com contextos socioambientais. A fim de fazer possível o que propõe Tristão (2008), são necessárias ações para a introdução da Educação Ambiental como tema transversal nos currículos, devendo ela, portanto, permear todo o processo de ensino-aprendizagem, em todos os estágios e modalidades admitidos na legislação vigente para a educação no país.

No que concerne à Educação Ambiental em instituições de ensino superior, concordamos com Tristão (2008), pois acreditamos que as universidades, principalmente as que possuem cursos de formação de professores em ciências, estão preparando profissionais cujas práticas poderão trazer consequências diretas para o ambiente. Portanto, defendemos formações constituídas de conhecimentos diversificados, permeadas de discussões mais amplas, com repercussão na sociedade, e não apenas na caracterização de abordagem aleatória da temática.

De acordo com Gerbase et al. (2005), essa é uma preocupação pertinente, pois os departamentos de Química, ou outras unidades que utilizam produtos químicos, deparam-se, ao longo de muitos anos, com diversos problemas envolvendo a necessidade de manejo e tratamento adequado dos resíduos, gerados em aulas práticas e/ou pesquisas, e nem sempre dispõem de um programa que promova um tratamento adequado para esses produtos, persistindo a prática de descarte de resíduos diretamente na pia, atitude incoerente, que contribui para possíveis problemas ao ambiente, ressaltados por Domingues, Guarnieri e Streit (2016). Sobre esse aspecto, Jardim (1998) e Abreu, Campos e Aguilar (2008) atentam para a necessidade de se ampliarem, em instituições de ensino superior, os questionamentos sobre o manejo adequado. Acreditamos que esse posicionamento na formação inicial do professor de Química é de grande significância, principalmente por envolver a preservação do próprio objeto de estudo e, mais que isso, segundo Giloni-Lima e Lima (2008), as instituições precisam reconhecer a posição em que estão, de geradora de resíduos. Gerbase et al. (2005) corroboram que essa é uma ação que deve ser encarada coletivamente, por toda a comunidade científica, a fim de se fazer cumprir a Lei $n^{\circ}$ 12.305, que institui a Política Nacional dos Resíduos Sólidos, cujo conteúdo atribui a responsabilidade do gerenciamento de resíduos sólidos, incluídos os perigosos e excluindo os radioativos, aos próprios geradores e ao poder público. 


\section{RECURSOS METODOLÓGICOS}

Para atender à pergunta da pesquisa, lançamos mão da pesquisa qualitativa, que, na concepção de Godoy (1995), objetiva a melhor compreensão de um fenômeno no contexto em que está inserido, cabendo ao pesquisador, com base em uma análise integrada, percebê-lo mediante as perspectivas dos sujeitos envolvidos. Chizotti (2010, p. 84) complementa que "procura-se compreender a experiência que eles têm, as representações que formam e os conteúdos que elaboram". Quanto ao objetivo da pesquisa, esta classifica-se como descritiva, conforme Gil (2008), pois busca descrever os fatos e fenômenos de determinada realidade sem interferir nela.

O campo empírico constituiu-se do laboratório de aula e de pesquisa do CAA/UFPE, e, como sujeitos, tivemos dois grupos de licenciandos, matriculados entre o 3 ㅇ e o 10ㅇ períodos do curso. A escolha dos sujeitos esteve atrelada ao fato de eles possuírem algum contato com o Laboratório de Química e se encontrarem em processo de formação inicial de professores. Assim, temos o primeiro grupo, caracterizado por dez licenciandos que utilizam o laboratório apenas em aulas experimentais realizadas pelos docentes da universidade; e o segundo grupo, constituído por nove licenciandos que também fazem uso do laboratório para desenvolver pesquisas. A apreensão e o registro dos dados deram-se a partir de entrevista semiestruturada, registrada em áudio, construída com questões-chave relacionadas à pergunta da pesquisa e realizada ao final das disciplinas laboratoriais, individualmente, com os dezenove licenciandos.

Para a apreciação dos dados, fizemos a transcrição do material gravado em áudio e, na sequência, os extratos analíticos da transcrição foram analisados, tendo como referência a análise de conteúdo na perspectiva de Bardin (1977), uma vez que pretendemos compreender, por meio das relações comunicativas, os fatores referentes ao problema estudado, mediante os conteúdos das falas e das ideias apresentadas pelos estudantes. A análise de conteúdo, segundo Bardin (1977, p. 95), consiste em "um conjunto de técnicas de análise das comunicações que utiliza procedimentos sistemáticos e objetivos de descrição do conteúdo das mensagens". Assim, a escolha dos extratos da entrevista esteve atrelada à obtenção de indicadores que permitissem a inferência de conhecimentos relativos ao manejo de resíduos, à responsabilidade e ao compromisso com a prática social no processo de manejo. 


\section{ANÁLISE DOS DADOS}

Na busca pelas respostas de nossas inquietações, a análise da nossa pesquisa foi realizada com base nas categorias apresentadas no Quadro 1.

Quadro 1 - Categorias evidenciadas na fala dos licenciandos durante a entrevista

\begin{tabular}{cc}
\hline Número da Categoria & Categorias \\
\hline I & Compreensão acerca do manejo de resíduos \\
II & Responsabilidade no processo de manejo \\
III & Compromisso com a reflexão como prática social \\
\hline
\end{tabular}

Fonte: elaborado pelos autores, 2016.

Recorremos a essas categorias por acreditarmos estarem de acordo com nossos objetivos. A construção delas levou em consideração as respostas obtidas que remetessem a aspectos de compreensão do tema em questão, "manejo de resíduos", atentando para reflexos dessa compreensão na prática social.

Para garantir o anonimato de cada entrevistado, os nomes reais foram substituídos por letras do alfabeto $(A, B, C . . ., I)$. Além disso, para distinguir os grupos, junto à letra do alfabeto acrescentou-se $(L a b)$, para os sujeitos pertencentes ao grupo que apenas usa o laboratório em aulas experimentais, e (Pesq), para os que usam laboratório para realizar, além das aulas experimentais, projetos de pesquisas.

Salientamos que a simbologia "[...]", nas transcrições, representa omissão de texto.

\section{Síntese da categoria "Compreensão acerca do manejo de resíduos"}

Nessa categoria, buscamos identificar aspectos das concepções dos licenciandos acerca da questão do manejo de resíduos, a partir das respostas apresentadas aos questionamentos que compunham a entrevista.

Observamos que os licenciandos, ao serem questionados sobre o que entendem a respeito de resíduos químicos, apresentaram, em maioria, insegurança e atribuem o conceito de resíduos a materiais que sobram das aulas experimentais e são posteriormente descartados. Seguindo a definição de resíduo de Machado e Mól (2008, p. 38), "são materiais remanescentes de 
alguma atividade realizada, que possuem potencial de uso após tratamento", no grupo Pesq, notamos alguns posicionamentos coerentes, como o de E-Pesq:

Vai ser todo aquele material que eu produzo e que eu posso, necessariamente ou não, fazer um descarte [...] o resíduo, eu posso conseguir reaproveitar uma parte [...] outra parte [...] fazer o descarte (E-Pesq).

Acreditamos que a participação na pesquisa deve ter proporcionado contribuição mais significativa para a compreensão acerca do manejo de resíduos, seja pelo fato de os estudantes engajados serem oportunizados a atividades de formação junto ao grupo de químicos responsáveis por esse segmento dos laboratórios seja pela maior aproximação com a prática dos docentes que coordenam e orientam as pesquisas. Dos extratos do grupo Lab, podemos sugerir que existem limitações de aprendizagem de conceitos, no que diz respeito ao manejo de resíduos ${ }^{3}$, uma vez que evidenciamos pouca ou nenhuma compreensão sobre o conceito. Registramos isso, por exemplo, no extrato de $C$-Lab:

Seria qualquer material que eu compre e se torne lixo? [...] (C-Lab).

Para fazer inferências mais consistentes sobre a compreensão do conceito de resíduo, questionamos os dois grupos sobre o que era feito com os resíduos após as aulas experimentais. Das respostas apresentadas, inferimos que os licenciandos limitam-se ao processo de descarte, desconsiderando o manejo necessário, conforme observado no extrato de $D$-Pesq:

Se ele prejudicar [...] é colocado num recipiente, depois um(a) técnico(a) leva para algum lugar que eu não sei (D-Pesq).

E de G-Lab:

[...] dependendo do reagente, a gente tem essa separação [...] algumas coisas, a gente joga na pia [...] quando tem algum resíduo que não pode ser a gente, o(a) professor(a) faz a separação, e os(as) técnicos(as) é quem fazem o descarte, não sei pra onde (G-Lab).

Ressaltamos que os demais entrevistados apresentaram respostas semelhantes a essas. Observamos que, além da informação do descarte dos resíduos na pia, não se faz outra

\footnotetext{
${ }^{3}$ Segundo Zabala (1998, p. 43) “[...]não podemos dizer que se aprendeu um conceito ou princípio se não se entendeu o significado".
} 
referência ao destino dos resíduos gerados. Conforme Gerbase e colaboradores (2005, p. 1), esse problema está relacionado à falta de "uma política institucional clara que permita um tratamento global do problema". Evidenciamos esse problema na citação do estudante $D$-Lab:

Ouvi dizer! [...] gerenciamento de resíduos no laboratório [...] nunca vi! [...] efetivamente funciona? (D-Lab).

Desse recorte, notamos incertezas, aparentemente caracterizadas por poucas discussões sobre o manejo de resíduos na formação desses licenciandos e evidenciamos ausência de reflexão nas atividades desenvolvidas, caracterizando ações mecânicas por parte dos licenciandos nas aulas experimentais.

Ao indagarmos os dois grupos acerca de quem manejava os resíduos químicos, embora dois licenciandos do grupo Pesq e um do Lab tenham atribuído aos próprios licenciandos o processo de manejo de resíduos, como F-Pesq:

[...] desde a pessoa que está envolvida no processo [...] não passar, essa responsabilidade pra um técnico(a) ou pra uma outra pessoa [...] você produziu, você tem que cuidar daquilo em todo momento (F-Pesq).

Ambos os grupos atribuíram essa competência aos(as) técnicos(as), como A-Lab:

Quem maneja [...] deve ser os(as) técnicos(as) [...] (A-Lab).

Diante desses recortes, podemos inferir que a maioria dos licenciandos demonstra pouca ou nenhuma compreensão de que o manejo adequado dos resíduos envolve/deve envolver todos os participantes que o geram na prática visto que, dentre todos os entrevistados, apenas três conseguem trazer (conscientes ou não do conceito que envolvem) a inserção da própria participação no processo, bem como a preocupação de utilizar técnicas que a ação (antes programa) de gerenciamento de resíduos defende que sejam feitas para minimização dos impactos ambientais. Entretanto, Gerbase e colaboradores (2005, p. 1) afirmam que "essa questão precisa ser encarada coletivamente por toda a comunidade científica e pelos órgãos de fomento, dada sua relevância".

Corroborando com os autores, acreditamos que o levantamento de discussões que contemplem a coletividade na formação desses licenciandos possibilitaria mais posicionamentos semelhantes ao do licenciando F-Pesq. 
Ao questionarmos sobre a participação no manejo dos resíduos, obtivemos respostas como Mínima![...] os resíduos ficam guardados para os(as) técnicos(as) manejarem (C-Pesq).

$E$

Nenhuma![...] o(a) professor(a) diz pra colocar dentro do Becker (I-Lab).

Essas respostas sugerem o despreparo dos licenciandos para lidar com os resíduos produzidos nos laboratórios de Química e a participação mínima dos sujeitos, concentrada no armazenamento dos resíduos em recipientes indicados pelo professor, sugerindo limitações no processo de ensino-aprendizagem de conteúdos procedimentais de Zabala (1998).

\section{Síntese da categoria "Responsabilidade no processo de manejo"}

Nessa categoria, atentou-se para o discernimento dos licenciandos de se incluírem como responsáveis no processo de manejo dos resíduos, levando em consideração a Lei $n^{\circ} 12.305$, de 2 de agosto de 2010.

Inicialmente, questionamos os licenciandos sobre o conhecimento da lei supracitada. Do grupo $L a b$, apenas $C$-Lab diz ter conhecimento sobre. No Pesq, a situação observada repete-se com F-Pesq dizendo ter tido certas aproximações em algumas descrições sucintas em roteiros de práticas e por meio do Projeto Pedagógico do Curso (PPC).

De acordo com Domingues, Guarnieri e Streit (2016), se os responsáveis não se apropriam das exigências legais, muito provavelmente não irão preocupar-se com a responsabilidade do ciclo reverso do produto, o que contribuiria para maiores impactos negativos ao meio ambiente.

Quando os questionamos sobre quem achavam ser responsável pelos resíduos gerados no laboratório de química, D-Lab traz:

Acho que os(as) técnicos(as) [...] é o que é passado pra gente [...] acho errado [...] a gente era pra ter acesso a isso [...] (D-Lab).

C-Pesq: 
[...] os primeiros responsáveis são os(as) alunos(as) e o(a) professor(a) que fizeram o experimento. Mas aqui temos noção de que o responsável mesmo é o(a) técnico(a) [...] (C-Pesq).

Um licenciando do grupo Lab não soube responder.

No recorte feito, para o $D$-Lab, mesmo não mostrando segurança em indicar um responsável, há a preocupação em ser partícipe do processo, quando faz menção a uma das tipologias de conteúdo (conteúdo procedimental) de Zabala (1998). Segundo o autor, essa tipologia inclui realização de ações ordenadas, para alcançar um determinado objetivo. Porém, observando a citação do C-Pesq, evidencia-se que há uma cultura de remeter, dentro da universidade, a responsabilidade dos resíduos aos(às) técnicos(as); provavelmente, porque nas aulas experimentais não há discussões amplas sobre a temática.

Com relação à menção do(a) professor(a) como responsável pelos resíduos gerados, Machado e Mól (2008) discutem que a participação dos(as) professores(as) é de grande importância para o desenvolvimento de práticas que evitem a produção de um número excessivo de resíduos ou rejeitos e também para a promoção de debates sobre a temática numa perspectiva ampla, que englobe questões ambientais, políticas, sociais, culturais e econômicas, com os estudantes. Constata-se, pelo que expõem os autores, a necessidade de formar profissionais cuja atuação na sociedade seja permeada de comprometimento com o meio ambiente. Nesse sentido, concordamos com os autores, pois acreditamos que a formação dos licenciandos deve ser constituída de discussões que se afastem de discussões simplistas, ocorrendo de acordo com as Diretrizes Curriculares para a Educação Ambiental, de maneira articulada e interdisciplinar, numa perspectiva que não priorize apenas o aspecto cognitivo do processo pedagógico.

\section{Síntese da categoria "Compromisso com a reflexão como prática social"}

Procurando observar possíveis reflexos da formação dos licenciandos em suas ações futuras, nessa categoria, as entrevistas foram analisadas com base na perspectiva do professor reflexivo abordada por Zeichner (1993). Para o referido autor, professor reflexivo é aquele que considera a riqueza da experiência da prática dos bons professores, reconhece que o processo de aprender e ensinar prolonga-se por toda a carreira do professor e, além disso, na prática do ensino, há atenção e reflexão do professor para a prática e as condições sociais em que estiver inserida. 
Para a análise, destacamos os extratos dos estudantes F-Pesq, I-Lab e J-Lab, pelo motivo de levantarem pontos comuns aos demais entrevistados. Vale salientar que a indagação feita foi a respeito de como trabalhariam questões ambientais na escola, o futuro ambiente de trabalho deles.

\section{F-Pesq traz:}

Contextualizando [...] os assuntos [...] com outras disciplinas [...] levantando questões ambientais, sociais, cidadãs [...] e, dentro do possivel, demostrar experimento [...] que demonstrasse o reaproveitamento das coisas [...] (F-Pesq).

Do recorte, notamos a preocupação de trabalhar questões ambientais numa perspectiva que relacione a temática apresentada na sala de aula com os contextos social, ambiental e cidadão dos envolvidos, para promover no discente sensibilização com o meio ambiente em que está inserido. A fala do licenciando nos remete a Zeichner (1993), ao abordar atividades com a preocupação de trabalhar temáticas envolvendo não só os conteúdos químicos, mas também os aspectos sociais. Para Zeichner (1993, p. 25), "na prática do ensino reflexivo, a atenção do professor está tanto voltada para dentro, para a sua própria prática, como para fora, para as condições sociais nas quais se situa essa prática".

Analisando os extratos do $I$-Lab

Poderia usar a poluição dos rios, como aqui tem escassez de água [...] e também [...] a reciclagem do lixo, pois aqui não existe muito essa prática [...] (I-Lab).

E do $J-L a b$

[...] trabalharia questões ambientais na parte de óleo, para que eles pudessem reciclar o óleo produzindo sabão caseiro em sala de aula [...] (J-Lab).

Observamos que I-Lab preocupa-se em sensibilizar os discentes, relacionando as atividades com o contexto vivido na sociedade em que está inserido, algo peculiar à prática reflexiva, segundo Zeichner (1993). Já J-Lab busca trabalhar uma temática comumente utilizada por diversas escolas - a reciclagem. Nós consideramos esse tipo de atitude pouco reflexiva, pois, na maioria das vezes, os estudantes são solicitados a levar "lixo" para a escola, quando, na verdade, a própria instituição é potencial geradora de resíduos. Teoricamente, esses estudantes 
estariam sendo conduzidos a tentar resolver "o problema do mundo", enquanto deveriam refletir e desenvolver ações no sentido de minimizar os resíduos da própria escola. Segundo Abreu, Campos e Aguilar (2008), essa seria uma proposta pontual e individualista, pois limitase apenas a uma das ações do processo de manejo de resíduos. Na perspectiva de Zeichner (1993), esse aspecto individualista não permite que o professor confronte e transforme aspectos estruturais do seu trabalho, e, segundo o mesmo autor, "o bom ensino precisa de ter [...] a representação das disciplinas, o pensamento e compreensão dos alunos, as estratégias de ensino sugeridas pela investigação e as consequências sociais e os contextos de ensino" (ZEICHNER, 1993, p. 15). Concordamos com o autor, visto que discussões que priorizam apenas a preocupação de conscientizar os alunos sem reflexão mais ampla possibilitam a propagação de visões reducionistas e possivelmente de atitudes que remetem à racionalidade técnica.

\section{CONSIDERAÇÕES FINAIS}

O estudo realizado com os estudantes de Química-Licenciatura do CAA/UFPE possibilitou identificar que os licenciandos que participam de pesquisas no laboratório contemplaram, parcialmente, a categoria "Compreensão acerca do manejo de resíduos", apresentando respostas mais coerentes para a definição do termo "manejo de resíduos". Pressupomos que a participação desse grupo em pesquisas possa ter proporcionado contribuição mais significativa para essa compreensão, seja pelo fato de os licenciandos engajados serem oportunizados a atividades de formação junto ao grupo de químicos responsáveis por esse segmento dos laboratórios seja pela maior aproximação com a prática dos docentes que coordenam e orientam as pesquisas.

Remetendo-nos ao grupo que apenas participou das aulas, constatamos algumas limitações quanto à compreensão acerca do manejo de resíduos, não contemplando a categoria supracitada. Supõe-se, com base em nossos aportes teóricos, que a formação acadêmica desses licenciandos pouco tem contribuído para a articulação de conteúdos conceituais e procedimentais em torno da problemática em questão, uma vez que os licenciandos desse grupo atribuíram o conceito de resíduos a materiais que sobram das aulas experimentais e são posteriormente descartados. Verificamos, ainda, que as respostas desses licenciandos relacionadas ao destino dado aos resíduos provenientes das aulas experimentais limitam-se ao processo de descarte, desconsiderando a necessidade de tratamento dos resíduos. 
Para a categoria "Responsabilidade no processo de manejo", evidenciamos que os licenciandos não se apropriaram das exigências legais relacionadas ao manejo dos resíduos por eles produzidos e, portanto, não se incluem como responsáveis em tal ação. Daí, evidencia-se uma cultura de remeter, dentro da universidade, a responsabilidade dos resíduos aos(às) técnicos(as), provavelmente porque nas aulas experimentais não há discussões amplas sobre a temática. Dado o exposto, supomos que a formação dos licenciandos deve ser constituída de discussões que se afastem de discussões simplistas, de maneira articulada e interdisciplinar, numa perspectiva que não priorize apenas o aspecto cognitivo do processo pedagógico.

Consideramos que a categoria "Compromisso com a reflexão como prática social" foi a mais contemplada pelos sujeitos pesquisados. Mesmo diante de algumas limitações apresentadas nas categorias anteriores, notamos a preocupação de ambos os grupos em trabalhar questões ambientais numa perspectiva que relacione a temática apresentada na sala de aula com os contextos social, ambiental e cidadão dos envolvidos, para promover no discente sensibilização com o meio ambiente inserido. Baseados nesses aspectos, constatamos, em certa medida, o compromisso com a reflexão como prática social, aspecto relativo à prática reflexiva, que acreditamos ser de grande importância para a prática do futuro profissional docente.

Por fim, pensamos que o presente estudo contribuirá para a ampliação de discussões perspectivamente reflexivas na formação docente em Química, distanciando-se de uma formação pautada na racionalidade técnica. Além disso, apoiamos a ideia de que a ampliação das discussões no curso, envolvendo a temática "manejo adequado de resíduos", articulada com o contexto socioambiental e educacional, abriria precedentes para a propagação de práticas conscientes e limpas, minimizando possíveis danos ocasionados pelo descarte inadequado de resíduos no meio ambiente.

\section{REFERÊNCIAS}

ABREU, Daniela G.; CAMPOS, Maria L. A. M.; AGUILAR, Márcia B. R. Educação ambiental nas escolas da Região de Ribeirão Preto (SP): concepções orientadoras da prática docente e reflexões sobre a formação inicial de professores de Química. Química Nova, São Paulo, v. 31, n. 3, p. 688-693, 2008.

BARDIN, Laurence. Análise de conteúdo. Lisboa: Edições 70, 1977. 225 p. 
BRASIL. Lei n 9.795, de 27 de abril de 1999. Dispõe sobre a educação ambiental, institui a Política Nacional de Educação Ambiental e dá outras providências. Diário Oficial [da] República Federativa do Brasil, Brasília, DF, 28 abr. 1999. Disponível em: <http://www. planalto.gov.br/ccivil_03/leis/L9795.htm>. Acesso em: 8 jun. 2016.

BRASIL. Presidência da República. Casa Civil. Subchefia para Assuntos Jurídicos. Decreto $\mathrm{n}^{\circ}$ 4.281, de 25 de junho de 2002. Regulamenta a Lei ${ }^{\circ}$ 9.795, de 27 de abril de 1999, que institui a Política Nacional de Educação Ambiental, e dá outras providências. Brasília, DF, 2002. Disponível em: <http://www.planalto.gov.br/ccivil_03/decreto/2002/d4281.htm>. Acesso em: 3 fev. 2018.

BRASIL. Presidência da República Casa Civil. Subchefia para Assuntos Jurídicos. Lei $\mathrm{n}^{\circ}$ 12.305, de 2 de agosto de 2010. Institui a Política Nacional de Resíduos Sólidos; altera a Lei n ${ }^{\circ}$ 9.605, de 12 de fevereiro de 1998; e dá outras providências. Diário Oficial [da] República Federativa do Brasil, Brasília, DF, 03 ago. 2010. Disponível em: <http:// www. planalto.gov.br/ccivil_03/_ato2007-2010/2010/lei/l12305.htm>. Acesso em: 17 set. 2016.

BRASIL. Ministério da Educação. Resolução n 2, de 15 de junho de 2012. Estabelece as Diretrizes Curriculares Nacionais para a Educação Ambiental. Brasília, 2012. Disponível em: <http:// conferenciainfanto.mec.gov.br/images/conteudo/iv-cnijma/diretrizes.pdf >. Acesso em: 3 fev. 2018.

CHASSOT, Attico. I. Para que $(m)$ é útil o ensino? Alternativas para um ensino (de Química) mais crítico. Canoas: Ed. da ULBRA, 1995. 189 p.

CHIZZOTTI, Antonio. Pesquisa em ciências humanas e sociais. São Paulo: Cortez, 2010. p. 77-106.

DARSIE, Marta M. P.; CARVALHO, Anna M. P. O início da formação do professor reflexivo. Revista Faculdade de Educação, São Paulo, v. 22, n. 2, p. 90-108, 1996.

DEWEY, John. Democracia e educação. São Paulo: Companhia Editorial Nacional, 1959.

DOMINGUES, Gabriela S.; GUARNIERI, Patrícia; STREIT, Jorge A. C. Princípios e instrumentos da Política Nacional de Resíduos Sólidos: Educação Ambiental para implementação da Logística Reversa. Revista em Gestão, Inovação e Sustentabilidade, Brasília, v. 2, n. 1, p. 191-216, 2016.

GERBASE, Annelise E.; COELHO, Fernando S.; MACHADO, Patrícia F. L.; FERREIRA, Vitor F. Gerenciamento de resíduos químicos em instituições de ensino e pesquisa. Química Nova, São Paulo, v. 28, n. 1, p. 1, 2005. 
GIL, Antonio C. Métodos e técnicas de pesquisa social. São Paulo: Atlas, 2008. 219 p.

GILONI-LIMA, Patrícia C.; LIMA, Vanderlei A. Gestão integrada de resíduos químicos em instituições de ensino superior. Química Nova, São Paulo, v. 31, n. 6, p. 1.595-1.598, 2008.

GODOY, Arilda S. Pesquisa qualitativa: tipos fundamentais. Revista de Administração de Empresas, São Paulo, v. 35, n. 3, p. 20-29, 1995.

JARDIM, Wilson F. Gerenciamento de resíduos químicos em laboratórios de ensino e pesquisa. Química Nova, São Paulo, v. 21, n. 5, p. 671-673, 1998.

MACHADO, Patrícia F. L.; MÓL, Gerson S. Resíduos e rejeitos de aulas experimentais: o que fazer?. Química Nova na Escola, São Paulo, n. 27, p. 57-60, 2008.

MALDANER, Otavio A. A formação inicial e continuada de professores de Química: professores/pesquisadores. Ijuí: Ed. UNIJUÍ, 2000. 424 p.

MARTINS, Wanessa A.; ALBUQUERQUE, Walker G.; NUNES, Francisco M. S.; ALMEIDA, Rosangela N.; MORAIS, Carlos E. P. Análise da concepção da população do município de Pombal-PB, sobre o adequado gerenciamento dos resíduos sólidos. Revista Verde de Agroecologia e Desenvolvimento Sustentável, Pombal, v. 9, n. 2, p. 307-316, 2014.

MEDINA, Naná M. Breve Histórico da Educação Ambiental. [S. n: s. I.], p. 1-7, 2008. Disponível em: <http://docplayer.com.br/1415782-Artigo-breve-historico-da-educacaoambiental-nana-mininni-medina.html>. Acesso em: 18 set. 2016.

MINISTÉRIO DO MEIO AMBIENTE - MMA. Educação Ambiental. Brasília, 2017. Disponível em: <http://www.mma.gov.br/educacao-ambiental>. Acesso em: 25 maio 2017.

PEREIRA, Júlio E. D. Formação de professores: pesquisas, representações e poder. Belo Horizonte: Autêntica, 2000. 168 p.

PORTO, Marcelo F. S. Saúde, ambiente e desenvolvimento: reflexões sobre a experiência da COPASAD - Conferência Pan-Americana de Saúde e Ambiente no Contexto do Desenvolvimento Sustentável. Ciência \& Saúde, Porto Alegre, v. 3, n. 2, p. 33-46, 1998.

SCHÖN, Donald A. Formar professores como profissionais reflexivos. In: NÓVOA, A. (Org.). Os professores e sua formação. Lisboa: Dom Quixote, 1992. p. 77-91.

SCHÖN, Donald A. Educando o profissional reflexivo: um novo design para o ensino e a aprendizagem. Porto Alegre: Artmed, 2007. 255 p. 
SOUZA, Agilson N. Ações reflexivas na prática de ensino de Química. 2009. 112 f. Dissertação (Mestrado em Ensino de Ciências) - Universidade Federal Rural de Pernambuco, Recife, 2009.

SOUZA, Agilson N.; SILVA, Suely A.; SILVA, Rosane M. A. Ações reflexivas na prática de ensino de Química. Revista Ensaio, Belo Horizonte, v. 15, n. 1, p. 175-191, 2013.

SOUZA, Rodrigo A.; MARTINELI, Telma A. P. John Dewey e a formação de professores: Aspectos da Influência sobre a formação docente no Brasil. In: IX ENCONTRO NACIONAL DE EDUCAÇÃO - EDUCERE. III ENCONTRO SUL BRASILEIRO DE PSICOPEDAGOGIA. 9., 2009, Curitiba. Anais do IX EDUCERE, Curitiba: Champagnat, 2009, p. 10.762-10.776.

TARDIF, Maurice. Saberes docentes e formação profissional. Petrópolis-RJ: Vozes, 2014. $325 \mathrm{p}$.

TRISTÃO, Martha. A educação ambiental na formação de professores: redes de saberes. São Paulo: Annablume; Vitória: FACITEC, 2008. 236 p.

ZABALA, Antoni. A prática educativa: como ensinar. Porto Alegre: Artmed, 1998. 224 p.

ZEICHNER, Kenneth M. A formação reflexiva de professores: ideias e práticas. Lisboa: Educa, 1993. $131 \mathrm{p}$.

\section{Yrailma Katharine de Sousa}

Graduada em Química-Licenciatura pela UFPE (2016). Atualmente está cursando mestrado no Programa de Pós-Graduação em Educação em Ciências e Matemática, na linha de pesquisa Metodologias e Prática de Ensino de Ciências e Matemática.

yrailma-scc@hotmail.com

\section{Regina Célia Barbosa de Oliveira}

Graduada em Química Industrial (2003), mestra em Química Inorgânica (2005) e doutora em Ciências Marinhas Tropicais (2012) pela Universidade Federal do Ceará (UFC). Professora adjunta da UFPE, atuando no curso de Química-Licenciatura do NFD. Professora do Programa de Pós-Graduação em Ensino de Ciências e Matemática da UFPE, na linha de pesquisa Metodologias e Prática de Ensino de Ciências e Matemática.

rcbgina@gmail.com 


\section{Agilson Nascimento de Souza}

Graduado em Engenharia Química pela Universidade Católica de Pernambuco (1993), licenciado em Química (1999) pela Universidade Federal Rural de Pernambuco, mestre em Ensino de Ciências (2009) pela mesma universidade. Químico na UFPE e professor do ensino básico na rede estadual de Pernambuco. Possui experiência em ensino de Química, formação docente e Química Analítica Instrumental, e atua predominantemente nas áreas de pesquisas de ensino de Química e formação docente.

agilson_ns@yahoo.com.br 